\title{
Erratum to: Invasion dynamics on a temperate rocky shore: from early invasion to establishment of a marine invader
}

\author{
Nancy J. O'Connor
}

Published online: 17 January 2014

(C) Springer Science+Business Media Dordrecht 2014

\section{Erratum to: Biol Invasions (2014) 16:73-87 DOI 10.1007/s10530-013-0504-1}

In Table 1 of the original publication, the word 'Panopeidae' was not displayed correctly in the final column in the electronic PDF and printed version of the article, whereas it is correct in the HTML version. The corrected version of Table 1 is shown in this erratum:

Table 1 Location of rocky shores selected for sampling crab populations in Massachusetts and Rhode Island, USA

\begin{tabular}{|c|c|c|c|c|c|}
\hline Town, state & $\begin{array}{l}\text { Latitude, } \\
\text { longitude }\end{array}$ & $\begin{array}{l}\text { Nearest body } \\
\text { of water }\end{array}$ & Description & $\begin{array}{l}\text { Duration of } \\
\text { sampling }\end{array}$ & $\begin{array}{l}\text { Resident } \\
\text { species }\end{array}$ \\
\hline $\begin{array}{l}\text { Scituate, } \\
\text { Massachusetts }\end{array}$ & $\begin{array}{l}42^{\circ} 11^{\prime} 47.83^{\prime \prime} \mathrm{N} \\
70^{\circ} 42^{\prime} 56.63^{\prime \prime} \mathrm{W}\end{array}$ & $\begin{array}{l}\text { Massachusetts } \\
\text { Bay }\end{array}$ & $\begin{array}{l}\text { Boulders and cobbles on gravel base } \\
\text { exposed to east and northeast winds }\end{array}$ & 1999-2011 & $\begin{array}{r}\text { Carcinus } \\
\text { maenas }\end{array}$ \\
\hline $\begin{array}{l}\text { Marshfield, } \\
\text { Massachusetts }\end{array}$ & $\begin{array}{l}42^{\circ} 5^{\prime} 45.32^{\prime \prime} \mathrm{N}, \\
70^{\circ} 38^{\prime} 53.19^{\prime \prime} \mathrm{W}\end{array}$ & $\begin{array}{l}\text { Massachusetts } \\
\text { Bay }\end{array}$ & Similar to Scituate & 1999-2011 & $\begin{array}{r}\text { Carcinus } \\
\text { maenas }\end{array}$ \\
\hline $\begin{array}{l}\text { Sandwich (Canal), } \\
\text { Massachusetts }\end{array}$ & $\begin{array}{l}41^{\circ} 46^{\prime} 37.11^{\prime \prime} \mathrm{N} \\
70^{\circ} 29^{\prime} 51.30^{\prime \prime} \mathrm{W}\end{array}$ & $\begin{array}{l}\text { Cape Cod } \\
\text { Canal }\end{array}$ & $\begin{array}{l}\text { Boulders and cobbles lining eastern end of } \\
\text { canal }\end{array}$ & 1998-2002 & $\begin{array}{r}\text { Carcinus } \\
\text { maenas }\end{array}$ \\
\hline $\begin{array}{l}\text { Sandwich (Bay), } \\
\text { Massachusetts }\end{array}$ & $\begin{array}{l}41^{\circ} 46^{\prime} 22.24^{\prime \prime} \mathrm{N} \\
70^{\circ} 29^{\prime} 31.14^{\prime \prime} \mathrm{W}\end{array}$ & Cape Cod Bay & Boulders and cobbles on sandy base & 1996-2002 & $\begin{array}{r}\text { Carcinus } \\
\text { maenas }\end{array}$ \\
\hline $\begin{array}{l}\text { Dennis, } \\
\text { Massachusetts }\end{array}$ & $\begin{array}{l}41^{\circ} 45^{\prime} 7.36^{\prime \prime} \mathrm{N} \\
70^{\circ} 11^{\prime} 22.31^{\prime \prime} \mathrm{W}\end{array}$ & Cape Cod Bay & $\begin{array}{l}\text { Small area of cobbles and boulders } \\
\text { bordered by sandy beaches }\end{array}$ & 1997-2002 & $\begin{array}{r}\text { Carcinus } \\
\text { maenas }\end{array}$ \\
\hline $\begin{array}{l}\text { Falmouth, } \\
\text { Massachusetts }\end{array}$ & $\begin{array}{l}41^{\circ} 33^{\prime} 8.05^{\prime \prime} \mathrm{N} \\
70^{\circ} 32^{\prime} 35.61^{\prime \prime} \mathrm{W}\end{array}$ & $\begin{array}{l}\text { Vineyard } \\
\text { Sound }\end{array}$ & $\begin{array}{l}\text { Small patch of cobbles and gravel bordered } \\
\text { by sandy beaches }\end{array}$ & 1996-2001 & Panopeidae \\
\hline $\begin{array}{l}\text { Bristol, Rhode } \\
\text { Island }\end{array}$ & $\begin{array}{l}41^{\circ} 38^{\prime} 37.19^{\prime \prime} \mathrm{N} \\
71^{\circ} 15^{\prime} 32.93^{\prime \prime} \mathrm{W}\end{array}$ & $\begin{array}{l}\text { Narragansett } \\
\text { Bay }\end{array}$ & $\begin{array}{l}\text { Boulders and cobbles over sand and silt } \\
\text { base }\end{array}$ & 1998-2010 & Panopeidae \\
\hline
\end{tabular}

The online version of the original article can be found under doi:10.1007/s10530-013-0504-1.

\section{N. J. O’Connor $(\bowtie)$}

Department of Biology, University of Massachusetts

Dartmouth, N. Dartmouth, MA 02747, USA

e-mail: noconnor@umassd.edu 